\section{"Determinacy"}

It is on this account that we have developed in our clinic the concept of " determinacy" to contrast with " significance." If the result of a trial is determinant we mean that it will determine a course of action, and determinacy therefore depends on the degree of difference between two methods of treatment. Determinacy is not necessarily correlated with significance. For instance, it would be true to say that if the difference between two methods of treatment were significant, and the significantly better treatment was equally acceptable on other grounds, then determinacy and significance would be positively correlated. If, on the other hand, the trouble and anxiety associated with one method of treatment were far in excess of the other, and the difference between these treatments was not significant, then the trial would nevertheless be highly determinant in favour of the second. In planning our trials, therefore, we first decide what levels of significance we are prepared to accept, and, as we have seen, this need not be the same for one of the possible results as for the other, but we also decide what difference we are going to regard as determinant. In the standard " $t$ " test this can readily be done by deciding what difference in means we would regard as determinant. Here again different levels of determinacy may apply, depending upon which of the two methods is to be preferred.

Lastly, we must turn to the fallacy deriving from the heterogeneity of the population to be contrasted in a controlled clinical trial. If we took two populations of patients with advanced cancer of the breast, matched appropriately for age, stage of the disease, nature of the deposits, and so on, and conducted a trial on this population to see which was the more effective method of treatment-by androgens or by oestrogens-we might find that androgens were to be preferred, taking the population as a whole, and this result might completely swamp the undoubted preference for oestrogens in the older age group. By suitable stratification, and by examining groups within the population, such an effect would be detected, but this may not be possible.

In the Medical Research Council trial to test the relative merits of cortisone and aspirin in the treatment of rheumatoid arthritis, no significant difference emerged between the merits of these two methods. This has often been wrongly interpreted as implying that the M.R.C. trial suggested that in any individual patient it did not matter whether you prescribed cortisone or aspirin. The trial was not in fact designed to test this, and it would be improper, therefore, to draw conclusions of this nature from it.

If there are problems-ethical, scientific, and even mathematical-associated with controlled trials it nevertheless remains the case that this technique holds out greater promise for advance in therapy than any yet devised. More important, however, is it that recognition of the scientific basis upon which such trials are constituted will ensure, so far as is possible, that the undesirable state of affairs prevailing in medicine during the first half of this century will never be repeated to the extent of producing so many false trails and so many unnecessary and unworthy modes of therapy.

\section{Summary}

Before the introduction of the method of the controlled clinical trial after the second world war important discoveries in medicine occurred at infrequent intervals. Those that have stood the test of time were of such a nature that there could be no denying their efficacy, and no trial was necessary in order to show this. On the other hand, a number of unsound methods of therapy were introduced and enjoyed a temporary vogue-for instance, many of the methods based on the theory of focal sepsis, operations for intractable duodenal ulcer, and the like. These methods of therapy led to considerable and quite unnecessary suffering before they were discarded.

With the development of the controlled clinical trial by Sir Austin Bradford Hill this whole situation is being changed for the better. Nowadays a therapeutic measure must stand up to the most stringent tests before it can be accepted as effective. As the controlled clinical trial must involve randomization, the gravest problems of ethics obtrude. These problems are dealt with, and special reference is made to the questions relating to when a trial should be concluded, and to the probability levels which should be accepted in the event of one or other of the conflicting issues emerging as the one to be preferred.

The legal and ethical matters relating to the desirability of informing a patient that he is taking part in a trial are briefly discussed.

The concept of " determinacy" as opposed to " significance" is developed, and lastly the difficulties in interpretation of a trial arising from the heterogeneity of the population within the universe of discourse is considered.

\title{
Significance of Reactions to Intradermal Injection of Autologous Granulocytes, Mononuclear Cells, and Serum
}

\author{
A. VARELZIDIS,* DIPL.MED. ; J. L. TURK,* M.D., M.C.PATH.
}

Brit. med. F., 1966, 2, 379-382

A number of reports in the past six years have described skin reactions to the intradermal injection of autologous leucocytes in patients with systemic lupus erythematosus and discoid lupus erythematosus (Friedman, Bardawil, Merrill, and Hanau, 1960 ; Bennett and Holley, 1961 ; Tromovitch and March, 1961). Nikolic and Holborow (personal communication, 1962) and Gerstein and Knox (1963), however, failed to confirm these findings in both systemic and discoid lupus

\footnotetext{
* Department of Immunology, Institute of Dermatology, St. John's Hospital for Diseases of the Skin, London.
}

erythematosus. Other authors (Tuffanelli, 1964 ; Long and Uesu, 1964) have described similar reactions in scleroderma and pyoderma gangrenosum. The present investigation is an attempt to resolve these differences. First, polyvinylpyrrolidone was used to separate leucocytes because of the known antigenic properties of dextran, which has been employed by previous authors. Secondly, it was possible to make a partial separation of granulocytes and mononuclear cells by differential centrifugation. Particular emphasis was placed on diseases such as lupus erythematosus, in which positive skin reactions to autologous leucocytes had been previously reported. Other condi- 
tions examined were vasculitis of possible immunological origin, diseases of the reticuloendothelial system involving the skin, eczematous conditions with secondary eruptions, and a wide range of other diseases of the skin.

\section{Materials and Methods}

Sterile glassware was used throughout. From a vein in the antecubital fossa $35 \mathrm{ml}$. of blood was drawn under aseptic conditions. The blood was divided into two aliquots and defibrinated by gentle swirling for about 10 minutes in two Erlenmeyer flasks, each containing eight glass beads. Then 15 $\mathrm{ml}$. of defibrinated blood was placed in each of two siliconized $50-\mathrm{ml}$. centrifuge tubes and thoroughly mixed with $6 \mathrm{ml}$. of $3.5 \%$ polyvinylpyrrolidone (Polyvidone) dissolved in $0.15 \mathrm{M}$ $\mathrm{NaCl}$. The erythrocytes were allowed to sediment for one and a half to two hours at room temperature. The supernatant was removed and centrifuged in $10-\mathrm{ml}$. siliconized graduated conical centrifuge tubes at $130 \mathrm{~g}$ for five minutes. The supernatant from the first centrifugation was recentrifuged in fresh $10-\mathrm{ml}$. siliconized graduated conical centrifuge tubes at $450 \mathrm{~g}$ for five minutes. The pellets from both centrifugations were resuspended in $3.5 \%$ polyvinylpyrrolidone to $0.5 \mathrm{ml}$. Counts were made of the leucocyte concentration of both pellets, and the concentration of cells from the first centrifugation was adjusted so as to be equal to that of the second-this was 6.5$8 \times 10^{7} / \mathrm{ml}$. Differential counts were made of cells from each preparation. The cells in the pellet from the first centrifugation consisted of $75-90 \%$ granulocytes, whereas the cells from the second pellet consisted of $80-90 \%$ mononuclear cells. Both preparations were contaminated with erythrocytes, the granulocyte fraction containing one-third more than the mononuclear fractions.

An intradermal injection of $0.1 \mathrm{ml}$. of each fraction was made into the flexor aspect of the forearm of the patient of origin. Serum was prepared from clotted blood, and $0.1 \mathrm{ml}$. of undiluted serum was injected as well. Where positive reactions were found to both leucocyte fractions, $0.1 \mathrm{ml}$., containing $7 \times 10^{6}$ erythrocytes per ml., was injected intradermally, to make sure that the reactions were not due to erythrocyte contamination. All such controls were negative. In such cases $0.1 \mathrm{ml}$. of $3.5 \%$ polyvinylpyrrolidone was also injected intradermally and also found to produce consistently negative reactions. In the other cases the granulocyte fraction and mononuclear fractions were thought to control each other. Where patients reacted to serum, it was shown that they would not react nonspecifically to the intradermal injection of saline or polyvinylpyrrolidone.

Fifty-six of the patients were also skin-tested with $0.1 \mathrm{ml}$. of suspensions containing $5 \times 10^{8}$ bacteria $/ \mathrm{ml}$. of the following dead organisms: Staphylococcus aureus, Streptococcus (Lancefield group G), Str. salivarius, and Str. viridans; and $0.05 \mathrm{ml}$. of a suspension of $5 \times 10^{8} / \mathrm{ml}$. Staph. albus. These suspensions were obtained from Bencard Allergy Unit, Beecham Research Laboratories, Brentford, and contained $0.5 \%$ phenol as a preservative. All patients were also tested with a control solution containing the preservative only. None of the patients tested reacted to the control solution.

Skin reactions to both blood fractions and bacteria were observed half an hour, four hours, and 24 hours after skin tests. Reactions seen at half an hour were erythematous, sometimes with a central weal; these reactions were not indurated. Reactions at 4 and 24 hours were erythematous and indurated, those at 24 hours often resembling a positive tuberculin reaction.

Investigation into the presence of antinuclear factor in the serum of patients with discoid lupus erythematosus was carried out by Dr. K. Rhodes, of the Rheumatology Laboratory of the Department of Physical Medicine of the Royal Free Hospital, by means of weanling-rat liver and a rabbit antihuman $\gamma$-globulin conjugated with fluorescein isothiocyanate.

\section{Experimental Results}

Examination was made of 120 subjects presenting with a wide variety of skin diseases (Table I). Apart from reaction in patients with discoid lupus erythematosus and allergic vasculitis, only four patients out of 92 with other skin diseases were found to give positive skin reactions. One of the two patients with pemphigus vulgaris gave an immediate erythematous reaction of $30 \times 28 \mathrm{~mm}$. to the intradermal injection of mononuclear cells and of $12 \times 12 \mathrm{~mm}$. to the injection of serum-no reaction was given to the injection of granulocytes; these reactions were absent after one hour and no delayed reactions were seen. One patient out of the six with rosacea gave a $20 \times 25 \mathrm{~mm}$. delayed erythematous reaction, with induration at 24 hours, to mononuclear cells only. Two patients out of 17 with varicose eczema gave reactions: one gave a $30 \times 22$ $\mathrm{mm}$. delayed erythematous reaction at 24 hours with induration to mononuclear cells only, and the other gave $8 \times 9 \mathrm{~mm}$. delayed erythematous reactions at 24 hours to both granulocytes and mononuclear cells.

TABLE I.-Results of Skin Tests with Leucocytes and Serum in All

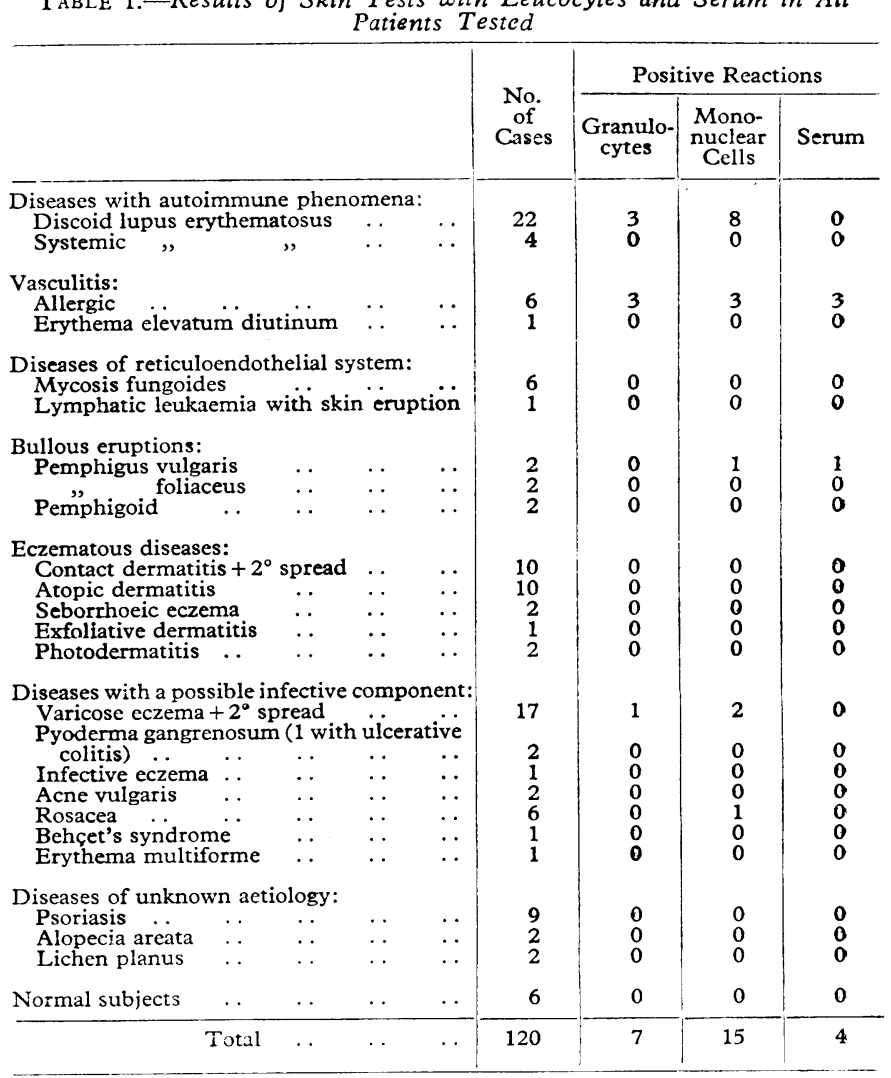

Table II presents an analysis of the reaction of patients with discoid lupus erythematosus. Immediate reactions were seen to granulocytes and delayed reactions to mononuclear cells. The presence of skin reactions was proportionate to the severity of the disease. No reactions were found to serum. No reaction was found in patients with systemic lupus erythematosus despite the fact that there was

\begin{tabular}{|c|c|c|c|c|c|c|c|c|}
\hline \multirow{4}{*}{$\begin{array}{l}\text { No. } \\
\text { of } \\
\text { Cases }\end{array}$} & \multirow{4}{*}{ Clinical Condition } & \multirow{4}{*}{$\begin{array}{c}\text { Positive } \\
\text { Anti- } \\
\text { nuclear } \\
\text { Factor }\end{array}$} & \multicolumn{6}{|c|}{ Skin-test Reactions } \\
\hline & & & \multicolumn{2}{|c|}{ Granulocytes } & \multicolumn{3}{|c|}{ Mononuclear Cells } & \multirow{3}{*}{ Serum } \\
\hline & & & \multirow{2}{*}{$30^{\prime}$} & \multirow{2}{*}{$24 \mathrm{hr}}$. & \multirow{2}{*}{$30^{\prime}$} & \multicolumn{2}{|c|}{$24 \mathrm{hr}}$. & \\
\hline & & & & & & ++ & + & \\
\hline \multirow{3}{*}{$\begin{array}{l}4 \\
6 \\
6\end{array}$} & \multirow{3}{*}{$\begin{array}{l}\text { Generalized but } \\
\text { without systemic } \\
\text { manifestations } \\
\text { Severe but localized } \\
\text { Disease only slightly } \\
\text { active .. .. }\end{array}$} & & 2 & 0 & 0 & 3 & 0 & \\
\hline & & 0 & $\overline{1}$ & 0 & 0 & 2 & 3 & 0 \\
\hline & & 0 & 0 & 0 & 0 & 0 & 1 & 0 \\
\hline
\end{tabular}

24-hour reaction to mononuclear cells erythema and induration (similar to tuberculin reaction):,$+ 7 \times 7-10 \times 10 \mathrm{~mm} .++,>10 \times 10 \mathrm{~mm}$.

$30^{\prime}$ reaction to granulocytes transient erythema with occasional central weal. 
widespread skin involvement, and both L.E. cells and the antinuclear factor were present.

Six patients with allergic vasculitis were studied (Table III). These could be readily subdivided into groups, depending on whether there was evidence of systemic involvement. The two patients with systemic involvement reacted only to the intradermal injection of their own mononuclear cells between 4 and 24 hours after injection. Clinically these patients never had haemorrhages and the disease was of the nodular variety. Of the four patients without systemic involvement three had haemorrhagic lesions. All four patients reacted to their serum and/or granulocytes, and three of them also to their mononuclear cells. The 24-hour reaction to injected granulocytes was shown histologically in one of these patients (see Fig.). It can be readily seen that the perivascular infiltrate consists mainly of mononuclear cells.

Fifty-six of the patients examined were tested for reactivity against suspensions of Staph. albus, Staph. aureus, Str. Lancefield group G, Str. salivarius, and Str. viridans (Table IV). Reactions to bacteria were more common in those patients with diseases where there was a possible infective component. However, reactions were no more intense in those giving skin reactions to the injection of their own mononuclear cells than in those who did not develop

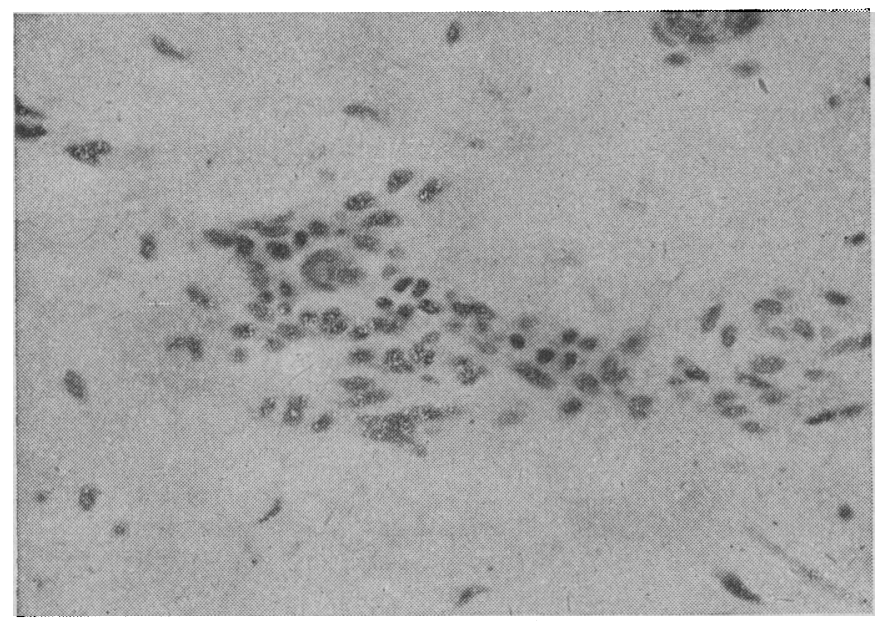

Twenty-four hours' delayed hypersensitivity reaction to the intradermal injection of autologous granulocytes in a patient with allergic vasculitis. Perivascular infiltration with mononuclear cells at a distance from the central deposit of granulocytes. (H. and E. $\times 350$.) such reactions. Only one significant fact was found-that the one patient out of 17 with a varicose ulcer who gave a severe delayedtype hypersensitivity reaction of $30 \times 22 \mathrm{~mm}$. to her own mononuclear cells, when injected intradermally, produced strong delayed reactions to tests with all five bacterial suspensions and immediate hypersensitivity to four of the five. Of the other 13 patients out of 20 with possible infective component who reacted to bacterial suspensions four produced immediate reactions to two out of the five suspensions and five reacted immediately to only one of the five suspensions. Seven developed delayed hypersensitivity to two out of the five suspensions and two to only one out of the five suspensions.

\section{Discussion}

There has been a certain amount of confusion in recent reports on the reactions of patients to the intradermal injection of their own leucocytes. This may partially stem from the fact that in all previous investigations injections were of whole leucocyte fractions of the blood and these were prepared by sedimentation of erythrocytes with dextran. Dextran is antigenic, and, though delayed hypersensitivity to it is not recorded, there have been a number of reports of anaphylactic reactions to both its systemic and its intradermal injection. In the present investigations polyvinylpyrrolidone was used to sediment erythrocytes, and a good functional separation of granulocytes and mononuclear cells was obtained. It was possible to show that reactions in the skin could be obtained not only with mononuclear cells, as might be expected, but also with granulocytes. The reactions seen were either immediate with erythema and oedema maximal 15 to 30 minutes after injections, or delayed with erythema and induration maximal 24 hours after injection. The immediate reactions often resembled those following the intradermal injection of histamine, and the delayed reactions closely resembled the tuberculin reaction. Similar immediate and delayed reactions to the intradermal injection of bacteria were also found.

In the case of immediate reactions to serum or granulocytes the presence of a pharmacological agent cannot be excluded. However, one must also consider the strong possibility that in some cases antigenic substances, either drugs or bacterial antigens, could be the cause of the reaction. The antigen

TABLE III.-Analysis of Skin Tests in Patients with Allergic Vasculitis of the Skin

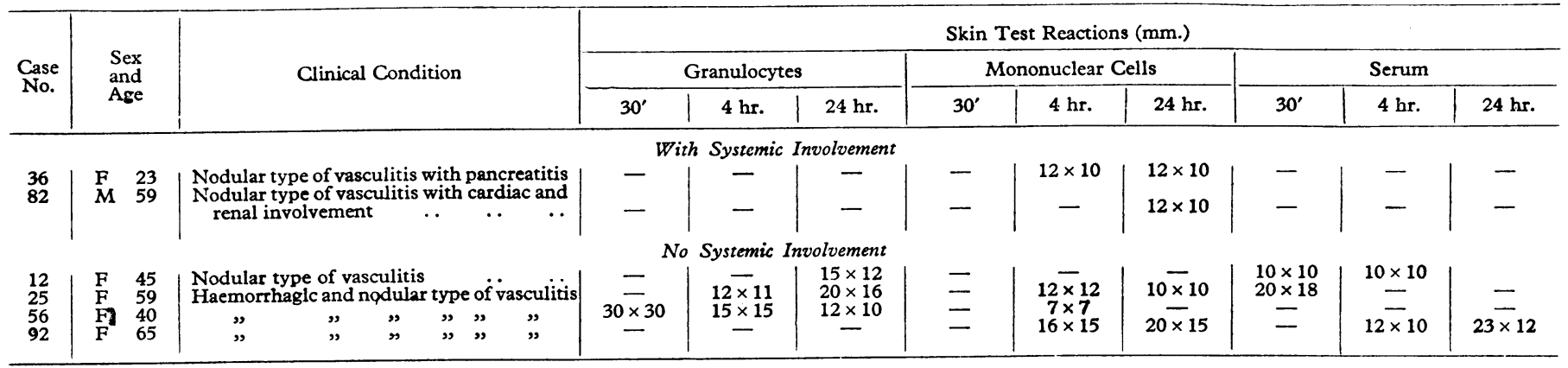

TABLE IV.-Analysis of Skin Reactions to Bacterial Antigens

\begin{tabular}{|c|c|c|c|c|c|c|c|c|c|c|c|c|c|}
\hline \multirow{2}{*}{ Disease } & \multirow{2}{*}{$\begin{array}{l}\text { Total } \\
\text { Cases } \\
\text { Exam- } \\
\text { ined }\end{array}$} & \multirow{2}{*}{$\underset{\text { cytes }}{\text { Granulo- }}$} & \multirow{2}{*}{$\begin{array}{c}\text { Mono- } \\
\text { nuclear } \\
\text { Cells }\end{array}$} & \multicolumn{2}{|c|}{$\begin{array}{l}\text { Staph. } \\
\text { albus }\end{array}$} & \multicolumn{2}{|c|}{$\begin{array}{l}\text { Staph. } \\
\text { aureus }\end{array}$} & \multicolumn{2}{|c|}{$\begin{array}{l}\text { Str. Lancefield } \\
\text { Group G }\end{array}$} & \multicolumn{2}{|c|}{$\begin{array}{c}\text { Str. } \\
\text { salivarius }\end{array}$} & \multicolumn{2}{|c|}{$\begin{array}{l}\text { Str. } \\
\text { viridans }\end{array}$} \\
\hline & & & & I. & D. & I. & D. & I. & D. & I. & D. & I. & D. \\
\hline $\begin{array}{l}\text { Disease with possible bacterial component } \\
\text { (varicose eczema, 10; pyoderma gan- } \\
\text { grenosum, } 2 \text {; infective eczema, } 1 \text {; acne } \\
\text { vulgaris, } 1 \text {; rosacea, } 6 \text { ) } \\
\text { Lupus erythematosus (discoid, } 14 \text {; systemic, }\end{array}$ & 20 & 1 & 3 & 7 & 4 & 7 & 5 & 2 & 5 & 1 & 3 & 0 & 2 \\
\hline 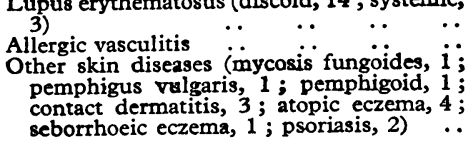 & $\begin{array}{r}17 \\
6\end{array}$ & $\begin{array}{l}2 \\
3\end{array}$ & $\begin{array}{l}6 \\
4\end{array}$ & $\begin{array}{l}2 \\
2\end{array}$ & $\begin{array}{l}0 \\
1\end{array}$ & $\begin{array}{l}1 \\
1\end{array}$ & $\begin{array}{l}1 \\
1\end{array}$ & $\begin{array}{l}0 \\
0\end{array}$ & $\begin{array}{l}1 \\
0\end{array}$ & $\begin{array}{l}0 \\
0\end{array}$ & $\begin{array}{l}\mathbf{0} \\
\mathbf{0}\end{array}$ & $\begin{array}{l}1 \\
0\end{array}$ & $\begin{array}{l}1 \\
0\end{array}$ \\
\hline
\end{tabular}


present in the serum or carried by granulocytes could react with a tissue-bound, reagin-like antibody. In the case of immediate reactions with serum, the presence of reagin-type antibodies in the serum directed against antigens in the skin is also possible. This should be especially considered in pemphigus vulgaris in view of the findings of Beutner and Jordon (1964) that in the serum of patients with pemphigus vulgaris there are antibodies which react with epidermal cells. These antibodies could either be directed against the body's own antigens as part of an autoimmune phenomenon or could be directed against bacterial or chemical antigens present in the skin.

Delayed hypersensitivity reactions to granulocytes could be explained only by the carriage of foreign antigens by these cells. In this connexion it is of interest that the perivascular cellular reaction at a distance from the granulocyte deposit is mononuclear, as in the tuberculin reaction. Delayed hypersensitivity reactions in the skin produced with lymphocytes could be the result of an autoimmune process, 'but the possibility that the cells are reacting with a foreign antigen in the skin, either of bacterial or of chemical origin, must also be examined. This must be seriously considered, particularly in the case of the patient with a varicose ulcer who developed a delayed hypersensitivity lesion when her own mononuclear cells were injected back intradermally. This patient was the only one out of the 56 skin-tested with bacteria who reacted to all five organisms. It is possible that this patient had become hypersensitive to many bacterial antigens that had been absorbed through her chronic ulcer, which had been present for many years. In fact her ulcer might have been acting in a manner similar to a Freund adjuvant granuloma in the experimental animal.

Delayed hypersensitivity reactions with mononuclear cells in cases of discoid lupus erythematosus could be due to an autoimmune phenomenon. It is, however, difficult to explain why negative reactions were found in the three cases of systemic lupus erythematosus with widespread skin manifestations, unless it is that the active cells in the blood had already reacted with the many antigenic sites present throughout the body in this disease.

In the present investigation it was possible to divide cases of allergic vasculitis of the skin into two groups on the basis of their skin reactions. The two patients with systemic manifestations developed delayed hypersensitivity reactions to their mononuclear cells only. Patients without systemic manifestations, three out of four of whom had haemorrhagic lesions, developed reactions either to granulocytes or to serum. In one case there was the interesting phenomenon of delayed hypersensitivity to autologous serum. It may be that the first group, with systemic manifestations, have a disease with an autoimmune phenomenon directed against vascular endothelium throughout the body. As a result of this there is a reaction when autologous mononuclear cells injected intradermally react with the vascular endothelium in the skin. In the second group of cases there may be foreign antigens circulating in the serum or carried by phagocytic cells such as granulocytes. It must be remembered that the mononuclear cell fraction contains $10-20 \%$ granulocytes as well as blood monocytes, which are also phagocytic, and this may account for smaller reactions with the mononuclear-cell fraction present at the same time as larger reactions to granulocytes or serum in some subjects. The antigen carried by phagocytes might be a drug or some bacterial breakdown product. This group of patients differed from the first by the presence of haemorrhagic lesions. However, no haemorrhages were produced by the intradermal injection of granulocytes, mononuclear cells, or serum, suggesting that an Arthus phenomenon was not involved.

Finally, the possibility that the reactions described are the result of reaction to bacterial contaminants on the surface of the skin must be considered. A much higher incidence of bacterial allergy was found in patients with a bacterial component in their disease, higher than was present in the diseases with the highest incidence of reactivity to granulocytes, mononuclear cells, or serum-discoid lupus erythematosus and allergic vasculitis. In only one case, discussed above, was there a strong indication that bacterial allergy could have been involved.

\section{Summary}

One hundred and twenty patients with various diseases of the skin were tested by the intradermal injection of their own granulocytes, mononuclear cells, and serum. A high incidence of reactions was found in discoid lupus erythematosus and allergic vasculitis. Reactions to all three components were found to be either immediate or similar to delayed-type hypersensitivity. Reactions in patients with discoid lupus erythematosus correlated well with the severity of the disease. In allergic vasculitis it was possible to divide the patients into two groups. Those with systemic manifestations reacted to their mononuclear cells only. Those without systemic manifestations-three out of four had haemorrhagic lesions-reacted to their serum or granulocytes and could have been manifestations of drug allergy. In most cases there was no correlation between positive reactions to leucocytes and skin reactions to five bacteria used in parallel skin tests.

We wish to thank those physicians, especially Professor C. D. Calnan, Dr. F. R. Bettley, and Dr. R. H. Meara, who referred patients to us for investigation, and Dr. Katerina Rhodes, of the Department of Physical Medicine, Royal Free Hospital, for the detection of antinuclear factor in the sera of the patients with discoid lupus erythematosus.

\section{REFERENCES}

Bennett, J. C., and Holley, H. L. (1961). Arthr. and Rheum., 4, 64. Beutner, E. H., and Jordon, R. E. (1964). Proc. Soc. exp. Biol. (N.Y.), 117,505 .

Friedman, E. A., Bardawil, W. A., Merrill, J. P., and Hanau, C. (1960). New Engl. F. Med., 262, 486.

Gerstein, W., and Knox, J. M. (1963). Brit. med. f., 2, 901.

Long, P. I., and Uesu, C. T. (1964). F. Amer. med. Ass., 187, 336.

Tromovitch, T. A., and March, C. (1961). 7. invest. Derm., 37, 345.

Tuffanelli, D. L. (1964). Ibid., 42, 179. 